\title{
The Acquisition of Definiteness and Specificity in English: A Case Study with Saudi-Arabic Learners of English Using an Online Task
}

\author{
Afnan Aboras ${ }^{1}$ \\ ${ }^{1}$ Collage of Arts and humanities, Swansea University, Swansea, United Kingdom \\ Correspondence: Afnan Aboras, Collage of Arts and humanities, Swansea University, Swansea, SA2 8PP, United \\ Kingdom. E-mail: afnan.aboras@gmail.com
}

Received: November 13, 2019 Accepted: December 12, 2019 Online Published: January 3, 2020

doi:10.5539/ells.v10n1p13 URL: https://doi.org/10.5539/ells.v10n1p13

\begin{abstract}
Definiteness with Arabic learners has been explored by many researchers such as Jaensch and Sarko (2009) and Sarko (2009). The majority of previous studies have used an offline task and focused on identifying the types of errors which learners were committing. Conversely, the present study will use an online reaction time task to investigate the learners' accuracy in judging [ \pm definite and \pm specific] in a series of sentences. The aim of the study is to ascertain the accuracy of participants in judging grammatical and ungrammatical sentences in terms of definiteness and specificity in English, and also to identify which factors have the greatest effect on this accuracy. The study will examine the process of article acquisition from the perspective of universal grammar using the following hypotheses: The Representational Deficit hypothesis (RDH) by Hawkins and Chan (1997), the Feature Reassembly hypothesis by Lardiere (2009) and the bottleneck hypothesis by Slabakova (2008, 2009, 2015) . Thirty-two Saudi learners have completed a grammatical judgment task that was designed using OpenSesame to incorporate a reaction time test along with two vocabulary tests (Yes/No and Lex30) and a proficiency test. The results showed no effect on definiteness and specificity with the Saudi-Arabic learners. Moreover, the findings demonstrated that there is no difference in reaction time which could be attributed to [ \pm definite and \pm specific]. Receptive vocabulary knowledge and proficiency affected the learners' accuracy in judging article use in English, but no such effect was found for the learners' productive vocabulary knowledge. Additionally, L1 negative transfer has been observed in Saudi-Arabic learners of English particularly with low-level learners.
\end{abstract}

Keywords: definiteness, specificity, Saudi-Arabic learners, reaction time, proficiency, vocabulary, L1 transfer

\section{Introduction}

Studies such as Al-qadi (2017), Albalawi (2016), Albaqami (2017) and Alhaysony (2012) have investigated the acquisition of the English definiteness system by Saudi-Arabic learners of English. These studies have focused on the errors that learners made while using English articles and the potential causes of these errors. Albalawi (2016) argued that article system usage errors were due to the effects of L1. Furthermore, Alhaysony (2012) argued that not only was L1 affecting the participants' article acquisition abilities, but the complexity of the English definiteness system had adverse effects, marking the issue as both interlingual and intralingual. This study will examine whether there is a difference between the time spend judging the definite and indefinite article, and what factors might affect this judgment. The study will first highlight the differences between Arabic and English in regard to definiteness and specificity to reveal how the languages differ in their article system, followed by the establishment of a theoretical framework and methodology, and finally, will provide results and further discussion.

\section{Feature Differences Between Arabic and English}

Definiteness in English have two articles (definite and indefinite). These could be denoted as 'definite and indefinite noun phrases, in that the definiteness or indefiniteness stems from the presence of the article, which has as its essential semantic function to express this category' (Lyons, 1999, p. 2). Definiteness is considered to be part of the functional morphology of all languages and is a universal semantic feature (Slabakova, 2013). There are many hypotheses concerning definiteness in the literature of semantics. Some of these theories include: the familiar and novel, the presupposition of existence, uniqueness and specificity and genericity. The indefinite article $(a, a n)$ is felicitous within novel contexts as expressed in (1). In contrast, the definite article (the) indicates that both the speaker and the listener have the same knowledge and are familiar with the same referent. 
1) I visited $a$ school (novel context). The school facilities were organized (familiar context).

In summary, the English language uses two articles (the indefinite and the definite) to express definiteness, specificity and genericity.

Definiteness in Arabic is affix that used to mark definite and indefinite in nouns (Lyons, 1999). The definite article uses the prefix ( $a l-)$ as shown in example (2). The indefinite article is indicated by the nunation $(-n)$, which is attached as a suffix as demonstrated in example (3) (Fassi Fehri, 2012). However, the indefinite article occurs in Modern Standard Arabic morphology in writing only (Awad, 2011). The indefinite article also occurs phonologically in Modern Standard Arabic exclusively (Abudalbuh, 2016). Arabic speakers with different dialects commonly drop the indefinite article. Al-Malki, Majid, and Mohd Omar (2014) found that most Arabic dialects tend to drop the indefinite article (nunnation), except in the cases of a few Bedouin dialects. Saudi Arabic speakers tend to drop the indefinite and the absence of the definite article (al-) by using bare nouns to indicate the indefinite context in Saudi Arabic. Dialects such as Syrian Arabic (Sarko, 2009) and Moroccan Arabic (Fassi Fehri, 2012) use the bare noun to denote the indefinite context. Therefore, definiteness in Arabic entails using the prefix (al-) for the definite context and bare nouns for the indefinite context.

2) al-kitab-u

The book

3) Kitab-u-n

"book - NOM-Nunation"

$A$ book

As for specificity, Ionin, Ko, and Wexler (2004) suggested that the distinguishing of the article in the language is based on definiteness or specificity. Ionin et al. (2004) provided a table that illustrates article choice distribution (1).

Table 1. The article choice parameters distribution by Ionin et al. (2004, p. 13)

Article distinguishes on definiteness

Article distinguishes on specificity

\begin{tabular}{lll}
\hline & + definite & -definite \\
\hline+ specific & & \\
-specific & & \\
\hline
\end{tabular}

\begin{tabular}{lll}
\hline & + definite & -definite \\
\hline+ specific & & \\
-specific & & \\
\hline
\end{tabular}

So, the language article system could be distributed according to definiteness or specificity. English uses definiteness to distribute the articles as does Arabic, and both languages follow the same distribution pattern. Which indicated that Arabic and English differ in their article system where Arabic use the definite article only but the English use both the definite and indefinite but both languages have the same distribution of definiteness and specificity.

\section{Hypotheses of Second Language Acquisition}

There have been many hypotheses that have focused on how L2 is acquired. Chomsky's universal grammar theory (1965) argues that all humans acquire language in the same manner. Many studies have investigated the legitimacy of universal grammar in regard to L2 learners and how L1 would affect the acquisition, such as the Representational Deficit hypothesis by Hawkins and Chan (1997), the Feature Reassembly hypothesis by Lardiere (2009), and the Bottleneck hypothesis by Slabakova $(2008,2009,2015)$. The Representational Deficit hypothesis by Hawkins and Chan (1997) argued that once the parameters of a first language are acquired, these parameters become fixed and are unable to be altered in the acquisition of a second language.

On the other hand, hypotheses such as Feature Reassembly by Lardiere (2009) suggest that learners are able to acquire features even if they were already fixed in their L1. Lardiere (2009) argued that learners possessed the ability to remap features from L1 to L2. The hypothesis suggests that learners go through two stages when acquiring language features, the first of which is mapping the features between L1 and L2 and the second is the reassembling of these features. Lardiere (2009) also argued that if learners had any difficulties or errors while 
using their L2 due to a feature being previously fixed in their L1, they would have to redistribute the feature to acquire it in their $\mathrm{L} 2$.

The Bottleneck hypothesis by Slabakova $(2008,2009,2015)$ suggests that functional morphology is the most difficult part of a language to acquire, since it differs between languages and the feature is tied to a variety of syntactic and semantic features. The findings indicate that the key to mastering the functional morphology of a target language is continual practice, suggesting that learners could acquire the feature even if it was already fixed in their L1. The Bottleneck hypothesis suggests that learners are able to obtain new language features, but some of these features (article use) would be much more difficult to acquire than others (semantics).

Feature Reassembly by Lardiere (2009) and the Bottleneck hypothesis by Slabakova $(2008,2009,2015)$ indicate that learners would still have access to the universal grammar and could acquire L2 features which have already been fixed in their L1. Moreover, the Bottleneck hypothesis suggests that learners can acquire the morphological features of L2. Feature Reassembly suggests that learners would be required to redistribute the feature in the target language if there were any difficulties or errors in their use of L2, a notion which runs contrary to the Representational Deficit hypothesis by Hawkins and Chan (1997). Representational Deficit hypothesis argues that learners would not be able to acquire a feature once it had been fixed in their L1.

\section{Research Questions and Predictions}

1) How accurately Saudi-Arabic learners would be in judge definiteness and specificity in English?

a- How accurately would they be in judge definiteness and specificity in English?

b- How accurately would they be in identify grammatical and ungrammatical sentences?

c- Would the Reaction Time (RT) differ according to definiteness and specificity?

d- Would Saudi-Arabic learners' accuracy and RT differ from native speakers of English?

2) What would affect the learners' accuracy in judging definiteness and specificity in English would it be vocabulary, proficiency or L1 transfer?

According to RDH, it is challenging for Saudi learners to acquire certain L2 features (such as definiteness) since they are already present and fixed in L1. As the definite article in L1 is the prefix ( $a l$-) (as in al-kitabu), learners need to acquire the L2 article (the). The indefinite article is the suffix (-n) (as in Kitab-u-n), but it is often omitted from speech and writing. In English, the indefinite article ( $a$ or $a n)$ is obligatory, unlike in Arabic and would not be able to acquire it in English.

The feature reassembly hypothesis predicts that learners would be able to acquire these features but would face difficulties with the indefinite article in L2 because of differing usage compared to L1, resulting in the indefinite article being dropped in L2 as in L1. For the indefinite article, learners would be required to remap the feature from L1 to the new feature in L2. Advanced learners would employ greater accuracy than beginners, but both would be capable of acquiring the feature.

According to the Bottleneck hypothesis by Slabakova (2008, 2009, 2015), the acquisition of English articles by Saudi-Arabic native speakers would be hindered by the functional lexicon. Confusion might result from a mismatch of functional morphology between L1 and L2. The Bottleneck hypothesis predicted that even advanced learners would have difficulties in assessing the sentences in the judgment task as well as add or omit articles unnecessarily because the functional lexicon of the English language. The predictions that the indefinite article would be more difficult for learners to employ than the definite article, since Saudi-Arabic omits the indefinite article. Consequently, it would be harder to gain a feature that is dropped in L1 according to the bottleneck because learners would not be able to map L1 features to L2.

These principles might also extend to reaction time (RT) (i.e., the amount of time taken to read the sentences), with times varying depending on which article was used in the sentence. Saudi-Arabic learners might spend more time on sentences using the indefinite as it is usually dropped in their L1.

\section{Methodology}

This section will introduce the participants, the instruments, the procedure and the data analysis. The methodology consisted of four tasks, and participants were required to finish all four in order to qualify for study participation.

\subsection{Participants}

The participants consisted of 32 Saudi-Arabic learners of English currently residing in the United Kingdom and studying at either the master or doctoral level. The group composition included 22 females and 10 males ranging in age from 25 to 37 years. 
The participants are students studying different fields, including biology, English language studies, English literature, translation, computer science, health care, and nursing. They were divided into two different English proficiency levels (a high-level group of 16 learners and a low-level group of 16 learners). Ten native speakers took part in the study to form a baseline.

\subsection{Instruments}

The primary instrument used in this study was a grammatical judgment task designed using the program OpenSesame by Mathôt, Schreij and Theeuwes (2012). The task consisted of 36 sentences (24 focused on articles and 12 fillers) adapted from Atay (2010) and Lee (2013). Having the conversations adapted from previous studies to rise the reliability and validity of the test. Twelve conversations focused on articles; these sentences were repeated twice, (once in the grammatically correct form and once in the incorrect form) resulting in 24 conversations in total as in the appendix A. The Yes/No test by Meara and Miralpeix (2015) measured the receptive knowledge of the participants using the website 'http://www.lognostics.co.uk/tools/V_YesNo/V_YesNo.htm'. The test is intended to measure vocabulary size; it was designed using the methodology established by Meara and Jones (1990) (the Eurocentres Vocabulary size test). The Yes/No test consisted of 200 words divided into two categories: real English words (hits) and imaginary English words (false alarms). The test would give the vocabulary that learners have up to 10,000 words which is suitable for advance learners. The Lex 30 vocabulary task by Meara and Fitzpatrick (2000) was used to measure the productive vocabulary knowledge of the participants. The website was 'http://www.lognostics.co.uk/tools/Lex30/index.htm'. Learners were required to provide the first four words that came to mind when presented with a stimulus, resulting in $120(30 \mathrm{x} 4)$ words in total. The test was a free productive task where learners could write any words which they deemed to be related to the stimulus. The Standardized Oxford proficiency test used in the studies of Jensen (2016) and Slabakova and García Mayo (2015). This test consists of 100 fill-in-the-gap sentences. I selected 40 sentences, each of which has a gap as in the appendix B using the program OpenSesame to design the task. The learners would be classified into two levels according to their score in Standardized Oxford proficiency test. The participants also completed a questionnaire to collect their personal information.

\subsection{Procedure}

The study was conducted online, and the participants were required to complete all four tasks. The students took up to one and a half hours to finish the tasks (some took less time). All participants commenced the study simultaneously. First, they were presented with the grammatical judgment task. The participants had to read 36 conversational sentences and judge them as being 1 (correct), 2 (incorrect) or 3 (I do not know). Second, in the Yes/No test, the subjects were given a word and a were asked if they knew it meaning; they could answer either Yes or $\mathrm{No}$, and the test would conclude once 200 words. Third, in the Lex30 test, participants had to write out the first four words that came to mind when given a word to read. This task was completed under a 30 second-per-word time limit (with an absolute time limit of 15 minutes). Lastly, in the Standardized Oxford proficiency test, participants were given 40 sentences, each with blank space, and were instructed to choose between three options to fill the blank space with.

\subsection{Data Analysis}

The data collected were analysed in terms of three parameters: First for definiteness (definite and indefinite article), next for specificity (+specific, +definite, +specific, -definite, -specific, +definite and -specific, -definite), and finally by sentence type (either grammatical or ungrammatical or filler).

As for reaction time, the results were captured with OpenSesame in milliseconds and have been converted into minutes. The data is presented according to definiteness (definite and indefinite article) and specificity (+specific, + definite, + specific, -definite, -specific, + definite and -specific, -definite) in order to demonstrate any differences in time spent reading.

\section{Results}

The results illustrate the judgement responses for the high-level, the low-level and the native speakers of English for definiteness and specificity according to the research questions of the study.

For (1a), the high-level and low-level groups demonstrated their ability to judge definiteness based on article use as shown in Figure 1. 


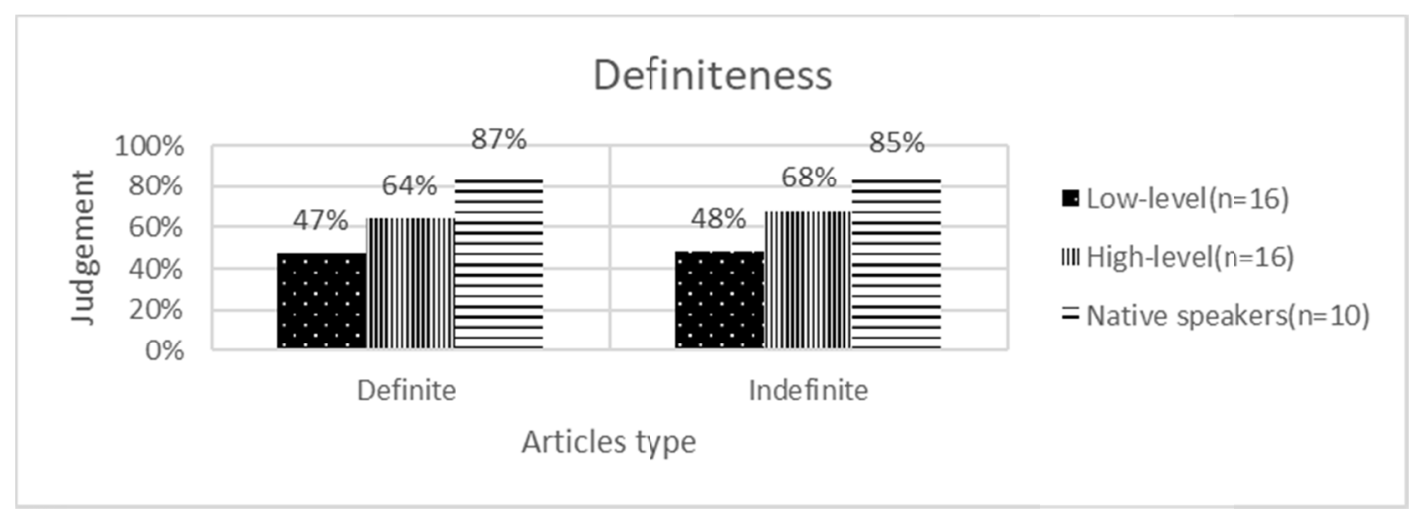

Figure 1. Definiteness judgement scores for all three groups

High-level learners scored $64 \%$ with the definite article and $68 \%$ with the indefinite article, whereas low-level learners scored $47 \%$ with the definite article and $48 \%$ with the indefinite article. Both high-level and low-level learners judged both the definite and indefinite articles without significant differences between articles. The native speakers were more accurate with the definite and the indefinite articles ( $87 \%$ and $85 \%$ receptively) as shown in Figure 1. As for specificity, Figure 2 illustrates the differences of the four types within and among the three groups.

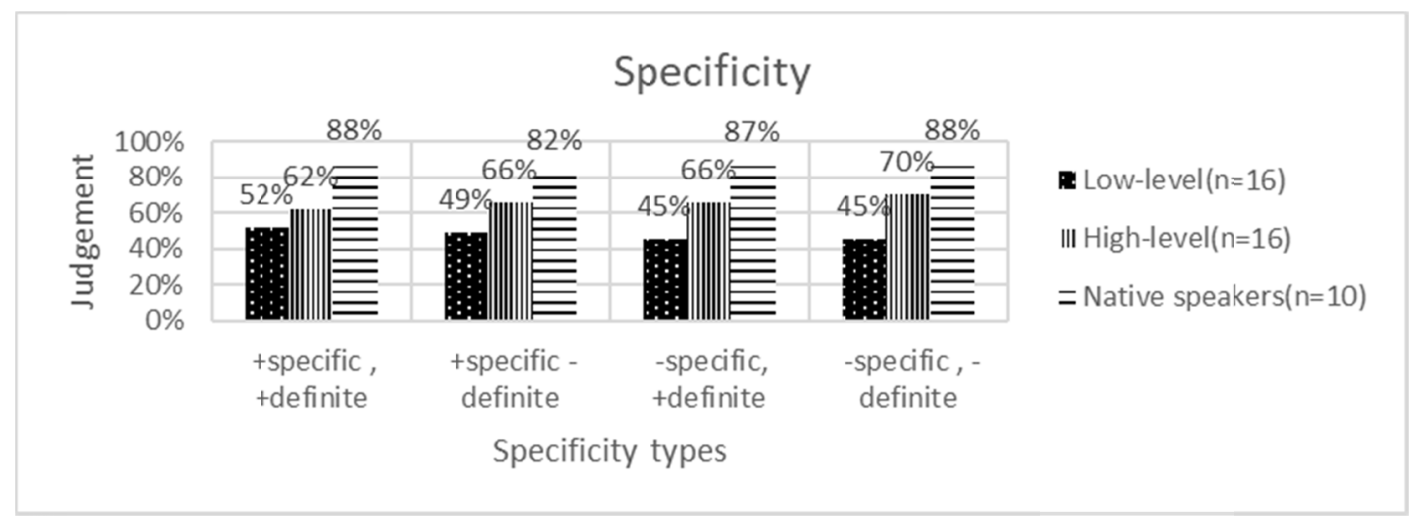

Figure 2. Specificity judgement scores for all three groups

For the high-level group, the results were: $62 \%$ for + specific, + definite; $66 \%$ with + specific, -definite; $66 \%$ with -specific, definite and 70 for -specific, -definite. For the low-level learners, +specific, +definite was 52\%; +specific, -definite was $49 \%$; -specific, definite was $45 \%$, as was -specific, -definite. The results for the four items in each group were not significantly different. Again, the high-level group was more accurate than the low-level group.

For (1b), Figure 2 demonstrates the judgement accuracy of grammatical and ungrammatical cases between the three groups. 


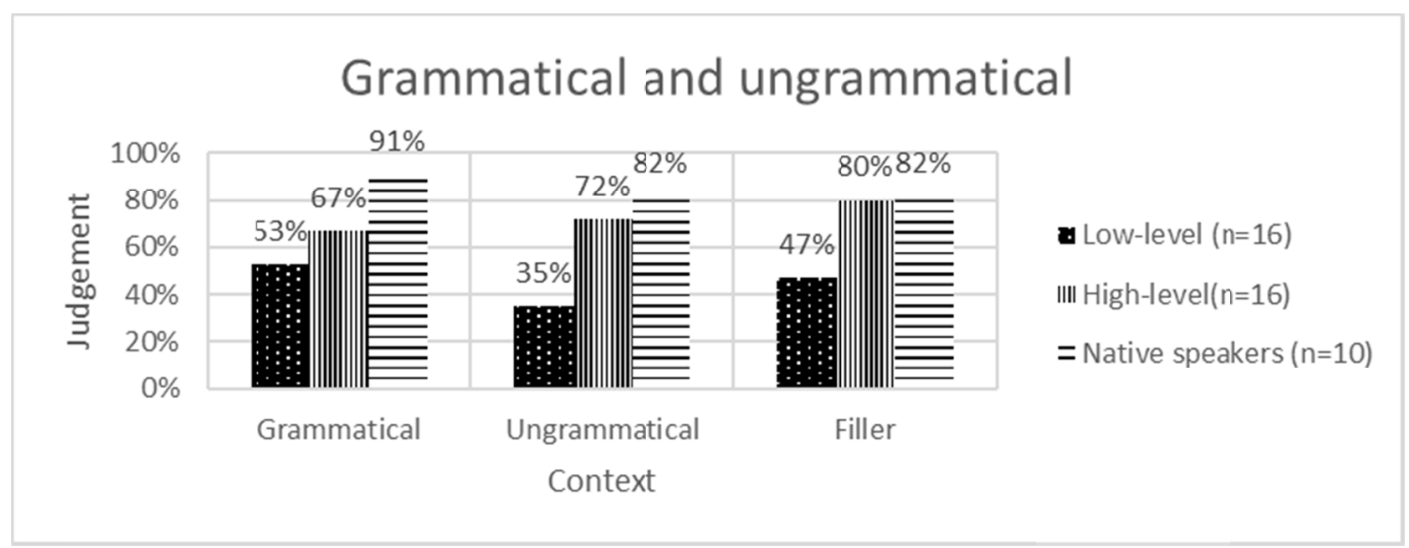

Figure 3. Grammatical and ungrammatical judgements for all three groups

The high-level learners judged the grammatical context with $67 \%$ accuracy, the ungrammatical with $72 \%$ and $80 \%$ for the filler statements. Comparatively, the low-level group was 53\% accurate for grammatical statements, $35 \%$ accurate for ungrammatical statements and $47 \%$ for the filler. Recognition of the grammatical context was high with both the high-level and low-level groups, but for both the ungrammatical and the filler statements high-level students were more accurate than low-level students. The native speakers scored highest with the grammatical context (91\%). They also identified $82 \%$ of both the ungrammatical and filler statements. Regarding RT, learners in both the high-level and low-level groups showed no demonstratable difference according to article type (4). Low-level learners spent more time reading than high-level learners; the low-level group spent 92 minutes for the definite article, 94 for the indefinite and 99 for the fillers. As for the high-level learners, they spent 76 minutes with the definite article, 69 minutes with indefinite article and 76 minutes with the fillers. Surprisingly, the high-level learners spent less time with indefinite article than with the definite article. Native speakers spent the least time reading with 21 minutes for the definite article, 19 for the indefinite and 18 for the fillers.

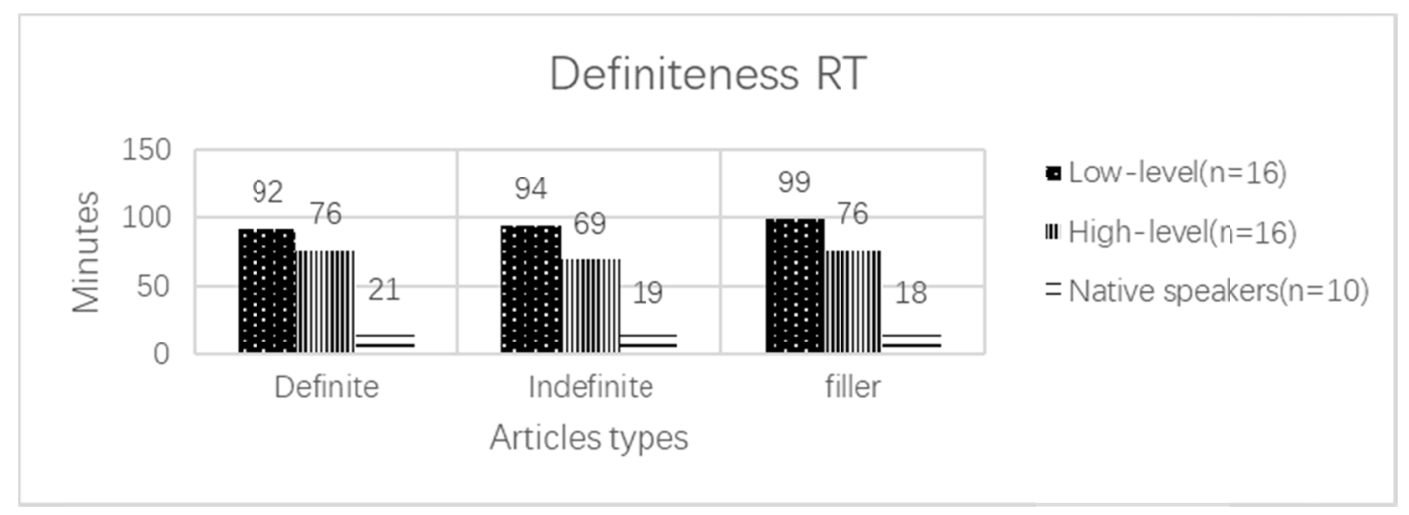

Figure 4. The reaction time for definiteness

As for specificity, Figure 5 illustrates the time spent with each of the four types. Again, the low-level group spent more time than the high-level group. The low-level group spent 42 minutes with +specific, +definite; 45 with +specific, -definite; 51 with -specific, definite and 46 with -specific, -definite. Comparatively, the high-level group spent, 33 with + specific, +definite; 38 with + specific, -definite; 36 with -specific, definite and 35 with -specific, -definite. The native speakers spent 10 minutes with + specific, + definite; 10 with + specific, -definite, and 9 for both -specific, definite and -specific, -definite. 


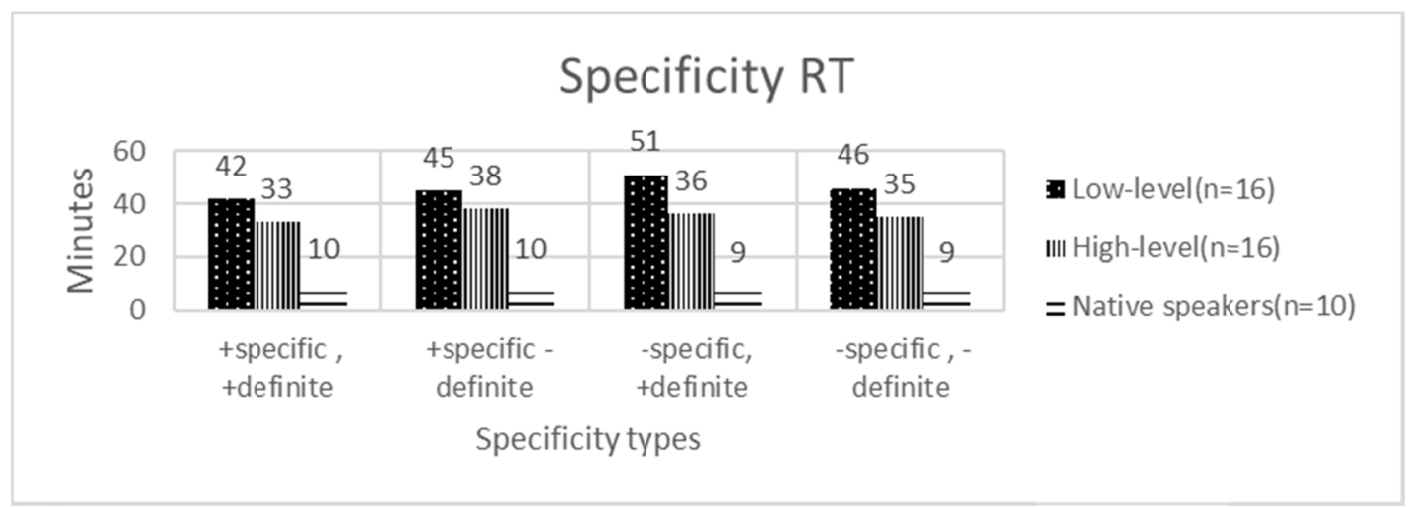

Figure 5. The reaction time for specificity

For definiteness and specificity, native speakers were more accurate than both high-level and low-level learners. Also, the native speakers scored higher on grammatical context with $91 \%$. As for the ungrammatical contexts, the native speakers got $82 \%$ which is quite close to the high-level learners with $72 \%$. The fillers also were similar between the native speakers and the high-level learners with $82 \%$ and $80 \%$ respectively.

The difference in reading time is high between the three groups. High-level and low-level learners spent much more time on reading than the native speakers.

As for the second research question, the mean and SD for the two-vocabulary test and the proficiency level test are presented in Table 2.

Table 2. The descriptive analysis for the vocabulary and proficiency tests

\begin{tabular}{llll}
\hline & Yes/No & Lex30 & Proficiency \\
\hline Valid & 32 & 32 & 32 \\
Mean & 4270 & 79.19 & 22.75 \\
SD & 1681 & 21.44 & 7.466 \\
Minimum & 1433 & 16.00 & 10.00 \\
Maximum & 7427 & 111.0 & 34.00 \\
\hline
\end{tabular}

The correlation between these three measurements and the three sentence categories (grammatical, ungrammatical or filler) is presented in Table 3.

Table 3. Pearson's correlation between the measurement tasks and the grammatical judgment task $(n=32)$

\begin{tabular}{llll}
\hline & & Person's r & P \\
\hline Grammatical conversations & -Proficiency & $0.402^{*}$ & 0.022 \\
Fillers & -Proficiency & $0.724^{* * *}$ & $<.001$ \\
Grammatical conversations & -Proficiency & $0.738^{* * *}$ & $<.001$ \\
Ungrammatical conversations & -Yes/No & $0.451^{* *}$ & 0.010 \\
Fillers & -Yes/No & $0.635^{* * *}$ & $<.001$ \\
Grammatical conversations & -Yes/No & $0.784^{* * *}$ & $<.001$ \\
Ungrammatical conversations & -Lex30 & -0.005 & 0.979 \\
Fillers & -Lex30 & 0.260 & 0.151 \\
\hline
\end{tabular}

Note. $* \mathrm{p}<.05, * * \mathrm{p}<.01, * * * \mathrm{p}<.001$.

The results revealed that there was a correlation between the respective vocabulary knowledge (Yes/No) and the proficiency level. No correlation was found between the grammatical judgment task and the productive vocabulary task (Lex30). 
Table 4. Pearson's correlation between ungrammatical conversations and the measurement task with high-level learners $(n=16)$

\begin{tabular}{llll}
\hline & & Person's r & P \\
\hline Ungrammatical conversations & -Proficiency & $0.650^{* *}$ & 0.005 \\
Ungrammatical conversations & -Yes/No & $0.568^{*}$ & 0.017 \\
Ungrammatical conversations & -Lex30 & 0.329 & 0.197 \\
\hline
\end{tabular}

A correlation which only applies to the high-level learners was also found, that being the correlation between the ungrammatical conversations and receptive vocabulary knowledge and proficiency level as shown in Table 4 .

\section{Discussion}

The aim of this study was to investigate the Saudi-Arabic learners' accuracy in judge definiteness and specificity using an online task and to determine which variables would affect the accuracy of their judgements.

As for (1a), the learners were able to judge definiteness and specificity. The high-level group was more accurate than the low-level group, but all learners demonstrated an ability to correctly judge definiteness and specificity in English. The predictions of the Representational Deficit hypothesis by Hawkins and Chan (1997) were contradicted by our results, as the learners were able to judge the sentences in terms of [ \pm definite and \pm specific]. The aforementioned hypothesis suggested that the learners would be unable to reset the L2 parameters and would consequently be constrained to the syntactic features of L1, but the participants were nonetheless able to gain the syntactic feature (definiteness) as seen in our judgment task results. The Saudi-Arabic learners of English were able to judge sentences in terms of definiteness and specificity, a feature which varies between Arabic and English, and the participants were able to acquire L2 parameters despite established fixation in L1. The high-level got 64\% for the definite and $68 \%$ for the indefinite article although the indefinite article is dropped in Arabic. The results are similar to those of Judy, Guijarro-Fuentes, and Rothman (2008), who discovered that native speakers of English were able to acquire Spanish DP features not present in L1, which also goes against RDH.

The Feature Reassembly hypothesis states that learners can use features in L1 to restructure their internal features. It also argues that the feature does not have to be transformed directly to L2, instead, it can be reassembled for use with L2. Learners demonstrated this flexibility by responding correctly to the sentences in the judgment task. Learners were able to reject ungrammatical sentences, which is evidence of acquisition of the feature. According to the Feature Reassembly hypothesis, learners would be able to gain the feature even if it was absent in their L1. This was demonstrated by Saudi-Arabic learners who acquired new features despite the differences between English and Arabic. The learners revealed their ability to use the nominal morphosyntax in L2 French and to fix and reset their L1 feature by reassembling between L1 and L2 as Lardiere (2009) suggested. The findings of Lardiere's study suggested that feature reassembly is essential in the acquisition of definiteness in Russian, and learners of Russian were similarly able to acquire new features. Other studies that support the Feature Reassembly hypothesis include Gil and Marsden (2013), Gil, Marsden and Whong (2011) and Herschensohn and Arteaga (2015).

The third hypothesis which I examined in the study is the bottleneck hypothesis by Slabakova $(2008,2009$, 2015). This hypothesis predicted that learners would be able to map their L1 definiteness with their L2 definiteness, but some difficulties would occur. First, definiteness is part of the functional lexicon which is, according to Slabakova, the bottleneck of second language acquisition. Even with advance learners, there might be some errors and difficulty resulting from the bottleneck. In this case, persistent practice is key to overcoming this hurdle. Our results indicated that students were similarly accurate with both the definite and the indefinite article.

As for (1b), the learners were able to judge grammatical correctness, but specificity had no effect on their accuracy. The learners were more accurate with the grammatical sentences than with the ungrammatical. The low-level learners were less accurate in identifying the ungrammatical context.

Our results contradict with the Representational Deficit hypothesis by Hawkins and Chan (1997). The learners were able to correctly select between the definite and the indefinite article and between the grammatical and ungrammatical sentences. Both high-level and low-level learners noticed the omission or the substitution of the correct article. Therefore, it can be ascertained that article use was established in their L2 syntactic system. The high-level learners have got $72 \%$ with the ungrammatical conversations and $82 \%$ with the native speakers which is quite close. As for the fillers the high-level got $80 \%$ and the native speakers got $82 \%$.

These results have confirmed the predictions of the Feature Reassembly hypothesis by Lardiere (2009), as the 
learners showed their ability to correctly judge the sentences. While the high-level students were more accurate, both groups distinguished between the grammatical and ungrammatical contexts despite the differences between $\mathrm{L} 1$ and $\mathrm{L} 2$.

Notably, low-level learners rejected only $35 \%$ of ungrammatical sentences, which might indicate persisting difficulties with definiteness and specificity which would likely be because of these three possible reasons:

1) The difficulties they are facing in the re-mapping between the indefinite article in L1 and L2.

2) Their L1 negative transfer caused by the difference between L1 and L2.

3) Learners are focusing more on the meaning than on the grammatical forms.

For the first case, Lardiere (2009) has suggested that learners might have difficulties in re-mapping items that differ between L1 and L2. The learners are facing problems in reconfiguring features between L1 and L2. The low-level learners demonstrated lower accuracy using the definite and indefinite article and in judging between grammatical and ungrammatical sentences.

The second reason is negative transfer. Ortega (2009) has shown, that there is negative and the positive transfer during the acquisition of L2. As there are differences between L1 and L2, negative transfer might occur when learners are relying on their L1 to acquire the new feature, a process which (Lardiere, 2009) refers to as re-mapping.

The third explanation for low accuracy is that learners are relying on the suggestions of Input processing (IP) (Vanpatten, 1990, 1996, 2007). This theory introduces principles aimed at highlighting the process of second language comprehension by proposing principles which might occur during comprehension. The principle relevant to our low-level learners' group is as follows: Learners will seek to derive meaning from the lexical items that are presented in the sentences before anything else. They tend to focus on the content lexical items of a sentence (girl, sleep) before the non-content lexical items (the, and, is). Definiteness is considered non-content, and learners would likely pay it less attention if they were trying to extract lexical content to form meaning. Attempting to process non-content words might lead them to ignore the information, which is not yet useful, preventing acquisition of the feature.

The next principle is related to lexical items, and is called 'the lexical preference principle' (VanPatten, 2007, p. 116). This theory suggests that learners will prioritise processing lexical items before the grammatical forms when they both carry the same semantic information. This results in reliance on the lexical items in a sentence to derive meaning. Low-level learners might have been focused more on the meaning than the features, which would explain why they accepted ungrammatical sentences more frequently than the high-level learners and the native speakers.

As for (1c), the high-level learners spent less time reading compared to the low-level learners. There was no notable difference between definiteness and specificity or between grammatical and ungrammatical sentences. These results run contrary to the predictions; I suspected that specificity or definiteness would influence RT.

The results of (1d) showed that the high-level learners performed similarly to the native speakers in their detection of filler sentences, demonstrating that proficiency affects this ability. The results indicated that the accuracy of both the high-level and low-level learners was lower than that of the native speakers. The high-level learners showed accuracy in filler detection which was very close to the accuracy of the native speakers with $80 \%$ and 82 respectively, but for definiteness, the high-level group scored notably lower than the native speakers as predicted by Ortega (2009), who surmised that learners who were acquiring a different article system than their L1 would face difficulties, even those who were intermediate or upper-level learners.

The high-level learners in the study also had difficulties with article use, but not to the same degree. As for the low-level learners, their judgement accuracy was low compared to the native speakers and the high-level learners, which could be (as (Choi, 2009) has indicated) due to differences between L1 and L2 which would make mapping more difficult for low-level learners. This hypothesis was supported by the comparatively high accuracy of the high-level learners. Slabakova (2013) has suggested that the more practice learners put in, the more sufficient they will be in functional morphology (the category which contains definiteness). Low-level learners require practice to be properly equipped for the difficulties of the mapping stage.

As for specificity, there was no differences between the four types (+specific, +definite; +specific, -definite; -specific, definite; -specific, -definite) within each group. The native speakers achieved similar results to the high-level and low-level groups. As in definiteness, native speakers scored higher than the high-level learners and the high-level learners scored higher than the low-level learners. The results showed insignificant differences 
between the four items inside each group; the differences were between groups only. These findings align with those of Jaensch and Sarko (2009).

Similarly, to the differentiation between the grammatical and ungrammatical context, the high-level group was able to recognize the errors more frequently than the low-level group (the latter group rejecting only $35 \%$ of incorrect sentences). This result was predicted by IP (VanPatten, 2007), that is, that low-level students would have been more focused on the meaning of sentences compared to the grammatical forms, which is why they were unable to reject many of the ungrammatical sentences.

So, as with the differences between the three groups, the native speakers and the high-level speakers were similarly accurate in their judgement of the fillers and rejection of the ungrammatical sentences. As for definiteness and specificity, the native speakers scored higher than both the high-level and the low-level learners.

Regarding the second research question, the learners performed differently regarding their judging of definiteness and specificity based on their level. As for their vocabulary and proficiency level, low-level learners faced difficulties recognizing and rejecting the ungrammatical contexts. Their low receptive vocabulary and proficiency negatively affected their judgement compared to the high-level learners who were able to identify and reject the ungrammatical contexts with similar accuracy to the native speakers. Also, the results showed a correlation between the ungrammatical conversations, the proficiency level and the receptive vocabulary knowledge with the high-level learners only. Additionally, the low-level learners identified only $47 \%$ of the filler statements. This indicates that a lack of receptive vocabulary and proficiency affected the low-level group's judgements of definiteness and specificity. No such correlation was found in the productive vocabulary task. According to these findings, learners require both a high receptive vocabulary level and a high proficiency level to accurately judge definiteness. Conversely, productive vocabulary knowledge did not show correlation with grammatical or ungrammatical contexts, only to filler contexts. This might be because the learners did not produce any articles, a possibly vital element for establishing correlation between Lex30 and definiteness. It should also be noted that the number of participants in the study was small, therefore, these results must be dealt with cautiously.

Our results showed that definiteness and specificity are affected by the learners' receptive vocabulary knowledge and their proficiency level in English. Moreover, learners appear to need a high vocabulary level (greater than 4,000 respective vocabulary knowledge) and a high proficiency level in order to be able to identify ungrammatical conversations and grammatical errors in sentences.

The results of Abudalbuh (2016) predicted that the level of proficiency would affect the Arabic-learners' accuracy with articles in English. Jaensch and Sarko (2009) also indicated that high-level learners would be more accurate than low-level learners regarding English articles due to the latter experiencing mapping difficulties.

As for the L1 transfer, definite and indefinite judgement for the high-level learners was dissimilar to the native speakers (with $64 \%$ for the definite and $68 \%$ for the indefinite $87 \%$ for the definite and $85 \%$ for the indefinite respectively). As the high-level learners have high proficiency and a high receptive vocabulary, the impact on their performance could be due to latent L1 differences that have yet to be overcome. Ortega (2009) has suggested that upper-intermediate learners with an L1 article system that is different from English would face difficulties despite their relative proficiency. Our results also coordinate with Snape (2008) who found that even advanced Spanish-speaking learners of English had difficulties with plural mass due to difficulties in L1 transfer in a manner akin to the problems encountered by the Arabic learners in the present study. Jarvis and Odlinc (2000) have shown that Finnish speakers have similar difficulties with English article use due to L1 transfer.

Therefore, Saudi-Arabic learners require a high level of receptive vocabulary and proficiency to accurately identify ungrammatical contexts and to properly judge definiteness and specificity. High-level learners face similar but diminished difficulties compared to low-level learners, especially regarding definiteness and specificity (due to L1 transfer).

Briefly, the results showed that learners were able to judge grammatical and ungrammatical contexts. As for the roles of definiteness and specificity, the results did not show any notable differences in the learners' accuracy. The learners showed comparable accuracy using the definite and indefinite article. The only impact of the learners' level on the results was their proficiency in detecting ungrammatical contexts. Low-level learners found it especially difficult to identify grammatical errors. The findings indicated that high-level Saudi Learners were able to accurately judge the definite and indefinite article unlike the low-level learners who have been still affected by the L1 negative transfer. The learners also need high receptive vocabulary knowledge to be accurate in judging the ungrammatical conversations. 


\section{Conclusion}

This study has investigated the accuracy of Saudi-Arabic leaners of English in judging definiteness and specificity. English and Arabic both have an article system, although these respective systems differ between languages. The Arabic article system drops the indefinite article and solely uses the definite article, making different than the English article system, which uses both. The 32 Saudi-Arabic learners were tasked with completing a grammatical judgement task, two vocabulary tests and a proficiency test. The results showed that the participants were able to identify both the definite and the indefinite article, and neither definiteness nor specificity affected their ability to judge the correctness of sentences. The Saudi-Arabic learners' proficiency and receptive vocabulary likely had impact more than the degree of L1 transfer. There was no noteworthy effect on the productive vocabulary task. The high-level learners were able to judge with more accuracy than the low-level learners. Additionally, the high-level learners performed similarly to the native speakers in identifying the ungrammatical context and the fillers. However, both high-level and low-level learners performed dissimilarly to the native speakers in terms of definiteness and specificity as being less accurate, a result which might indicate L1 influence. Finally, there was no difference in reaction time caused by definiteness or specificity, instead, RT was chiefly affected by sentence length.

\section{References}

Abudalbuh, M. (2016). The Acquisition of English Articles by Arabic L2-English learners: A Semantic Approach. Arab World English Journal, 7(2), 104-117. https://doi.org/10.24093/awej/vol7no2.7

Al-Malki, E. A., Majid, N. A., \& Mohd Omar, N. A. (2014). Generic reference in English, Arabic and Malay: A cross linguistic typology and comparison. English Language Teaching, 7(11), 15-27. https://doi.org/10.5539/elt.v7n11p15

Al-qadi, M. M. (2017). English Article System Errors among Saudi Arab EFL Learners: A Case of the Preparatory Year English Program Learners of King Saud University. International Journal of English Language \& Translation Studies, 5(1), 69-77.

Albalawi, F. S. (2016). Investigating the effect of Grammatical Differences Between English (L2) and Arabic (L1) on Saudi Female Students' Writing of English. European Scientific Journal, 12(14), 1857-7881. https://doi.org/10.19044/esj.2016.v12n14p185

Albaqami, S. (2017). Causes of article use problems by Saudi postgraduate elcos students at Bangor University. International Journal of Current Research, 9(11), 60935-60940.

Alhaysony, M. (2012). An analysis of article errors among Saudi female EFL students: A case study. Asian Social Science, 8(12), 55-66. https://doi.org/10.5539/ass.v8n12p55

Atay, Z. (2010). Second language acquisition of the English article system by Turkish learners: The role of semantic notions (p. 113). Retrieved from http://etd.lib.metu.edu.tr/upload/12611970/index.pdf

Awad, D. (2011). The Acquistion of English Articles by Arabic learners. Lancaster.

Choi, M. H. (2009). The acquisition of wh-in-situ constructions in second language acquisition. Dissertation Abstracts International Section A: Humanities and Social Sciences, 70(5-A), 1640. Retrieved from http://ovidsp.ovid.com/ovidweb.cgi?T=JS\&PAGE=reference\&D=psyc6\&NEWS=N\&AN=2009-99210-042

Crompton, P. (2011). Article errors in the English writing of advanced L1 Arabic learners: The role of transfer. Asian EFL Journal, 50(February), 4-35. $\quad$ Retrieved from http://www.asian-efl-journal.com/PTA/February-2011-Crompton.pdf

Fassi Fehri, A. (2012). Key features and parameters in Arabic grammar Abdelkader Fassi Fehri (Linguistik Aktuell/Linguistics Today). Amsterdam; Philadelphia: J. Benjamins Pub. https://doi.org/10.1075/la.182

Gil, K. H., \& Marsden, H. (2013). Existential quantifiers in second language acquisition. Linguistic Approaches to Bilingualism, 3(2), 117-149. https://doi.org/10.1075/lab.3.2.01gil

Gil, K. H., Marsden, H., \& Whong, M. (2011). L2 acquisition of any: negative evidence, negative implicature and negative L1 transfer (pp. 29-39). Retrieved from http://eprints.whiterose.ac.uk/69759/

Hawkins, R., \& Chan, C. Y. H. (1997). The partial availability of Universal Grammar in second language acquisition: The 'failed functional features hypothesis'. Second Language Research, 13(3), 187-226. https://doi.org/10.1191/026765897671476153

Herschensohn, J., \& Arteaga, D. (2015). Parameters, Processing and Feature Reassembly in the L2 French Determiner Phrase. In The Acquisition of French in Multilingual Contexts (pp. 215-233). 
https://doi.org/10.21832/9781783094530-011

Ionin, T., Ko, H., \& Wexler, K. (2004). Article Semantics in L2 Acquisition: The Role of Specificity. Language Acquisition, 12(1), 3-69. https://doi.org/10.1207/s15327817la1201_2

Jaensch, C., \& Sarko, G. (2009). Sources of fluctuation in article choice in English and German by Syrian Arabic and Japanese native speakers. EUROSLA Yearbook, 9, 33-55. https://doi.org/10.1075/eurosla.9.04jae

Jarvis, S., \& Odlin, T. (2000). Morphological Type, Spatial Reference, and Language Transfer. Studies in Second Language Acquisition, 22(4), 535-556. https://doi.org/10.1017/s0272263100004034

Jensen, I. N. (2016). The Bottleneck Hypothesis in L2 acquisition: Norwegian L1 speakers' knowledge of syntax and morphology in English L2. The Arctic University of Norway.

Judy, T., Guijarro-Fuentes, P., \& Rothman, J. (2008). Adult Accessibility to L2 Representational Features: Evidence from the Spanish DP (pp. 1-21). Selected Proceedings of the 2007 Second Language Research Forum, 1998.

Lardiere, D. (2009). Some thoughts on the contrastive analysis of features in second language acquisition. Second Language Research, 25(2), 173-227. https://doi.org/10.1177/0267658308100283

Lee, J. (2013). A comprehensive study of the use of English articles by Korean L2 speakers of English. The State University of New Jersey.

Lyons, C. (1999). Basic observations. Definiteness, 1-46. https://doi.org/10.1017/CBO9780511605789.002

Mathôt, S., Schreij, D., \& Theeuwes, J. (2012). OpenSesame: An open-source, graphical experiment builder for the social sciences. Behavior Research Methods, 44, 314-324. https://doi.org/10.3758/s13428-011-0168-7

Meara, P., \& Fitzpatrick, T. (2000). Lex30: an improved method of assessing productive vocabulary in an L2. System, 28(1), 19-30. https://doi.org/10.1016/S0346-251X(99)00058-5

Meara, P., \& Jones, G. (1990). The Eurocentres Vocabulary Size Tests: 10KA. Zurich: Eurocentres.

Meara, P., \& Miralpeix, I. (2015). Tools for Vicabulary Research. Bristol. Multilingua Matters. Retrieved from http://www.lognostics.co.uk/tools/V_YesNo/V_YesNo_Manual.pdf

Ortega, L. (2009). Understanding second language acquisition. London: Hodder Education.

Sarko, G. (2009). L2 English article production by Arabic and French speakers. In M. P. G. Mayo \& R. Hawkins (Eds.), Second Language Acquisition of Articles: Empirical findings and theoretical implications (pp. 37-66). https://doi.org/10.1075/lald.49.06sar

Slabakova, R. (2008). Meaning in the Second Language. Berlin: Mouton de Gruyter. https://doi.org/10.1515/9783110211511

Slabakova, R. (2009). What is easy and what is hard to acquire in a second language (pp. 280-294). Second Language Acquisition Conference. https://doi.org/10.1075/aals.9.04ch1

Slabakova, R. (2013). The bottleneck of second language acquisition. Foreign Language Teaching and Research, $46(4), 5-28$.

Slabakova, R. (2015). What is easy and what is hard to acquire in a second language. In M. P. G. Mayo, M. J. G. Mangado \& M. M. Adrián (Eds.), Contemporary Approaches to Second Language Acquisition (pp. 5-28). https://doi.org/10.1075/aals.9.04ch1

Slabakova, R., \& García Mayo, M. D. P. (2015). The L3 syntax-discourse interface. Bilingualism, 18(2), 208-226. https://doi.org/10.1017/S1366728913000369

Snape, N. (2008). Resetting the Nominal Mapping Parameter in L2 English: Definite article use and the countmass distinction. Bilingualism: Language and Cognition, 11(01), 63-79. https://doi.org/10.1017/S1366728907003215

Vanpatten, B. (1990). ATTENDING TO FORM AND CONTENT IN THE INPUT An Experiment in Consciousness. Ssla, 12, 287-301. https://doi.org/10.1017/S0272263100009177

VanPatten, B. (1996). Input processing and grammar instruction in second language acquisition. Norwood: Ablex publishing corporation.

VanPatten, B. (2007). Input processing in adult SLA. In Theories in second language acquisition: An introduction (pp. 113-134). https://doi.org/10.4324/9781410615299 


\section{Appendix A}

\section{Grammatical judgment task}

1) grammatically correct.

A phone conversation

Susan: Hi, Mrs. Shepherd. Can I talk to Alice?

Mrs. Shepherd: Sorry Susan, but Alice is out. She went to the school library to work on her project.

2) ungrammatical context.

A phone conversation

Susan: Hi, Mrs. Shepherd. Can I talk to Alice?

*Mrs. Shepherd: Sorry Susan, but Alice is out. She went to school library to work on her project.

\section{Appendix B}

\section{Standardized Oxford proficiency test}

Fill the gap task with individual sentences.

1) Water at a temperature of $100^{\circ} \mathrm{C}$.

is to boil

is boiling

boils

2) The history of is

airplane

the airplane

an airplane

\section{Copyrights}

Copyright for this article is retained by the author, with first publication rights granted to the journal.

This is an open-access article distributed under the terms and conditions of the Creative Commons Attribution license (http://creativecommons.org/licenses/by/4.0/). 